\title{
Negative Linear Compressibility in Uranyl Squarate Monohydrate
}

\author{
Francisco Colmenero ${ }^{1}$, Joaquín Cobos ${ }^{2}$ and Vicente Timón ${ }^{1,2}$ \\ ${ }^{1}$ Departamento de Física Molecular, Instituto de Estructura de la Materia (IEM-CSIC), Madrid, Spain \\ ${ }^{2}$ Unidad de Residuos Radiactivos de Alta Actividad (URRAA-CIEMAT), Madrid, Spain \\ E-mail: francisco.colmenero@iem.cfmac.csic.es
}

Received xxxxxx

Accepted for publication $\mathrm{xxxxx \textrm {x }}$

Published xxxxxx

\begin{abstract}
The mechanical properties of the uranyl squarate monohydrate material, $\left(\mathrm{UO}_{2}\right)\left(\mathrm{C}_{4} \mathrm{O}_{4}\right) \cdot \mathrm{H}_{2} \mathrm{O}$, were studied using theoretical solid-state methods based in Density Functional Theory employing plane waves and pseudopotentials. Very demanding calculation parameters were utilized in order to obtain a realistic description of the mechanical behavior of this material. Since the determination of the positions of the hydrogen atoms in the unit cell of uranyl squarate monohydrate was not possible from X-ray diffraction data by structure refinement, they were fully optimized theoretically. The computed lattice parameters, bond distances, angles, and Xray powder diffraction patterns of this material were in very good agreement with the experimental data. This material was found to be mechanically and dynamically stable since the corresponding stability conditions were satisfied. The values of the bulk modulus and its pressure derivatives, shear and Young moduli, Poisson ratio, ductility, hardness, and mechanical anisotropy indices of this material were reported. Furthermore, this study showed that this material exhibits the important negative Poisson ratio (NPR) and negative linear compressibility (NLC) phenomena. Uranyl squarate monohydrate is a very anisotropic brittle material characterized by a bulk modulus of $\sim 33 \mathrm{GPa}$, which shows a minimum value of the NPR of the order of -0.5 . Besides, this material displays NLC values for a limited range of positive pressures, from $0.025 \mathrm{GPa}$ to $0.094 \mathrm{GPa}$, applied along the direction of minimum negative Poisson ratio. The analysis of the crystal structure as a function of pressure demonstrates that the mechanism of NLC of this material is associated to the change in shape of the uranyl pentagonal bipyramids and unrelated to the wine-rack structural mechanism commonly used to rationalize this phenomenon.
\end{abstract}

Keywords: uranyl-containing materials, mechanical properties, DFT, negative Poisson ratio, negative linear compressibility

\section{Introduction}

The cyclic oxocarbon acids $\left(\mathrm{C}_{\mathrm{n}} \mathrm{O}_{\mathrm{n}} \mathrm{H}_{2}, n=3,4,5,6\right)$ and their conjugated bases [1-5], the oxocarbon dianions $\left(\mathrm{C}_{n} \mathrm{O}_{n}^{2-}\right)$, have very interesting cyclic structures and possess very attractive physical and chemical properties, which have led to a large amount of applications of these materials. The anomalous mechanical behavior of the deltic, squaric, and croconic acids $(n=3,4,5)$ in the solid-state, which was never been investigated before using the experimental or theoretical methodologies, was unveiled in a recent work [6] and was found to be extremely interesting. These three materials exhibit negative Poisson ratios (NPR) [7-9] and the croconic acid displays the important negative linear compressibility 
phenomenon (NLC) [10-12] for external pressures larger than $0.4 \mathrm{GPa}$ applied along the direction of minimum Poisson ratio [6]. A complete review of the literature describing in detail the most important concepts, materials and applications of the NPR and NLC phenomena can alsò be found in this previous paper [6].

The purpose of this work is to study the mechanical behavior of a salt of the squaric acid, the uranyl squarate monohydrate (USM). This work is based in the utilization of rigorous theoretical solid-state methods employing a highquality computational setup. These methods were also used in recent works in order to study the NPR and NLC phenomena in the uranyl carbonate mineral rutherfordine and in the oxalic acid [13-14]. The description of solid-state crystalline compounds using computational modelling techniques, appears to be sufficiently advanced nowadays to predict their mechanical properties in good agreement with experimental values [15-40]. Following the pionering work by Keskar and Chelikowsky [15] in 1992 in which the anomalous mechanical behavior of crystalline $\mathrm{SiO}_{2}$ was studied theoretically, many other successsful studies were performed as those of Grima et al. [17] and Coudert et al. [18-19] on zeolites, Yao et al. [20] on crystalline cellulose, Tan et al. [21-22] on zeolitic imidazolate frameworks (ZIFs), Sun et al. [23] on pentagraphene and phagraphene, Du et al. [24] on black phosphorus, Li et al. [25] on an ammonium-zinc metalorganic framework, Qiao et al. [26] on ammonium oxalate monohydrate, Coates et al. [27] on $\mathrm{Cd}\left(\mathrm{NH}_{3}\right)_{2}\left[\mathrm{Cd}(\mathrm{CN})_{4}\right]$, Marmier et al. [28] on platinum sulfide and Kang et al. [29] on $\alpha-\mathrm{BiB}_{3} \mathrm{O}_{6}$.

While uranyl squarate monohydrate material has been synthetized and its structure was determined from X-ray diffraction experiments [41], the determination of the positions of the hydrogen atoms in its unit cell was not possible. Therefore, these positions were fully optimized in this work. The availability of these positions allowed the theoretical determination of the mechanical properties this material. This works shows that uranyl squarate monohydrate displays an anomalous mechanical behavior and exhibits the NPR and NLC phenomena. However, the mechanisms leading to these phenomena, encountered by analyzing the crystal structure of USM under the effect of pressure has been found to be completely different to those found in the previous work for the oxocarbon acids [6] and unrelated to the wine-rack structural mechanism [10-12].

Other uranyl salts of oxocarbon acids have been synthesized and characterized. For example, the synthesis and characterization of some uranyl squarate and croconate materials have been carried out by Rowland and Cahill [4243] and Basile et al. [44]. The use of metal-organic frameworks and coordination polymers containing uranium (VI) in a large number of research fields as catalysis, ion exchange, gas storage, and optics has been devised [45-50].
The mechanical properties of many of these compounds should be explored since many potential applications arising due to their mechanical behavior may be found.

This paper is organized as follows. The theoretical methodology used in this work is described in Section 2. Then, in Section 3, the main results of this work are given. This section contains three Subsections. In the first one, the structural properties of USM are studied and the positions of the hydrogen atoms in the unit cell of USM are reported. In the second Subsection, the X-ray diffraction pattern of USM is determined and compared with its experimental counterpart. In the last subsection, the mechanical properties of USM and the mechanical stability of its crystal structure is studied. In this subsection the anomalous mechanical behavior of USM is also described. Section 4 discusses the structural variations resulting from the application of pressure in the direction of minimum Poisson ratio, leading to the NPR and NLC phenomena in USM. Finally, the conclusions of this work are presented in Section 5.

\section{Theoretical methods}

The generalized gradient approximation (GGA) together with Perdew-Burke-Ernzerhof functional [51] supplemented with Grimme empirical dispersion correction [52], was used to study the crystal structure and mechanical properties of uranyl squarate monohydrate. The addition of dispersion corrections improved the computed structural and mechanical properties in a significant way as a consequence of the better description of the hydrogen bonding present in the unit cell of this material. This approach, referred to as DFT-D2, is implemented in the CASTEP program [53], a module of the Materials Studio package [54], which was employed to model the structure of USM. The pseudopotentials employed for the hydrogen, carbon and oxygen ions in the structures of these materials were standard norm-conserving pseudopotentials [55] provided by CASTEP. The norm-conserving relativistic pseudopotential employed for uranium ion was developed in in previous works [56-57] and has been employed extensively in the research of the structural, spectroscopic, thermodynamic and mechanical properties of uranyl containing materials [13,56-66].

The atomic positions and cell parameters were optimized by using the Broyden-Fletcher-Goldfarb-Shanno method [67-68] with a convergence threshold on atomic forces of 0.01 eV/Å. This method was also used in order to optimize the crystal structure of USM under the effect of different applied pressures. The structure was optimized in calculations with augmented complexity by increasing the calculation parameters. These parameters, the kinetic energy cut-off $(\varepsilon)$ and k-point mesh [69] were chosen to ensure good convergence for computed structure and energy. The structure was only considered to be satisfactory if the computed X-ray powder diffraction pattern determined from the computed 
crystal structure [70] was in agreement with the experimental pattern. The precise calculation parameters used to determine the final results are, $\varepsilon=950 \mathrm{eV}$ and a k-mesh of $6 \times 3 \times 3$ comprising $27 \mathrm{k}$-points.

The elements of the elasticity matrix needed to calculate the mechanical properties of the USM and to study the mechanical stability of its structure were obtained from stress-strain relationships employing the method of finite deformations [71]. In this technique, the individual elastic constants are determined from the stress tensor resulting from the response of the material to finite programmed symmetry-adapted strains [72]. The energy-based methods and the use of Density Functional Perturbation Theory [73] appear to be less efficient than this stress-based method for the calculation of the elasticity tensor [71]. The derivatives of the bulk modulus with respect to pressure were determined by performing fits of the unit cell volumes and associated pressures to a fourth-order Birch-Murnahan [74] equation of state (EOS). The unit cell volumes in the vicinity of the optimized structure were calculated by optimizing the geometry of the material considered under eighteen different applied isotropic pressures within -1.0 to $12.0 \mathrm{GPa}$. The fits of the pressurevolume data to the chosen EOS were carried out using EOSFIT 5.2 computer program [75].

The use of Hubbard correction [76] describing the strong Coulomb repulsion between electrons in $f$ orbitals was also evaluated in this work. However, as it will be seen in Section 3 , this correction, making significant improvements in the description of uranium containing systems in which uranium acts with IV oxidation state [77-82], appears not to be required in this case. In fact, for a large series of materials in which uranium acts with VI oxidation state, the standard DFT description provides very accurate results for their structures and properties [56-66,83-87].

\section{Results}

\subsection{Crystal structure}

The orthorhombic crystal structure of USM was optimized by performing increasingly complex computations using very demanding convergence criteria. The final calculations were performed with a large kinetic cut-off of $950 \mathrm{eV}$ and a k-mesh comprising $27 \mathrm{k}$-points. The calculated lattice parameters, volume, and density are given in Table 1, where they are compared with the experimental values given by Wilson [41]. The differences in the calculated cell volume and density compared with the experimental values were about $2.8 \%$. While the agreement is quite good, it must be noted that the theoretical results correspond to the temperature of $0 \mathrm{~K}$ and the experimental ones were obtained at ambient temperature. The comparison with the crystal structure obtained from the refinement of low temperature X-ray diffraction data should improve the comparison significantly $[88,6]$.
The results obtained by adding the Hubbard correction given in Table 1 are very close to those of the uncorrected DFT calculations. The Hubbard correction makes no appreciable contribution to system energy in this case. The energy is a very flat function of the Hubbard $U_{\text {eff }}$ parameter and, therefore, nearly the same results are obtained near the value, $U_{\text {eff }}=4.0$ $\mathrm{eV}$, determined by Weck et al. [80] for uranium dioxide. Because the introduction of Hubbard correction does not improve the description of USM significantly, it was not used to obtain the mechanical properties of USM reported below.

The computed crystal structure of USM is shown in Fig. 1, where views of the unit cell from [100], [010], and [001] directions are provided. The uranium atom in the crystal structure of USM displays pentagonal bipyramid coordination. The uranyl polyhedra are linked through the squarate ions, $\mathrm{C}_{4} \mathrm{O}_{4}^{2-}$. Each squarate ion provides one oxygen to the equatorial pentagons of four different pentagonal bipyramids (see Fig. 1.A). The vertices of the equatorial pentagons are occupied by oxygen atoms from squarate ions except one, which is occupied by a water molecule. The uranyl ion $\mathrm{UO}_{2}^{2+}$ in USM is nearly linear, the $\mathrm{Ou}-\mathrm{U}-\mathrm{Ou}$ angle being very close to $180^{\circ}$.
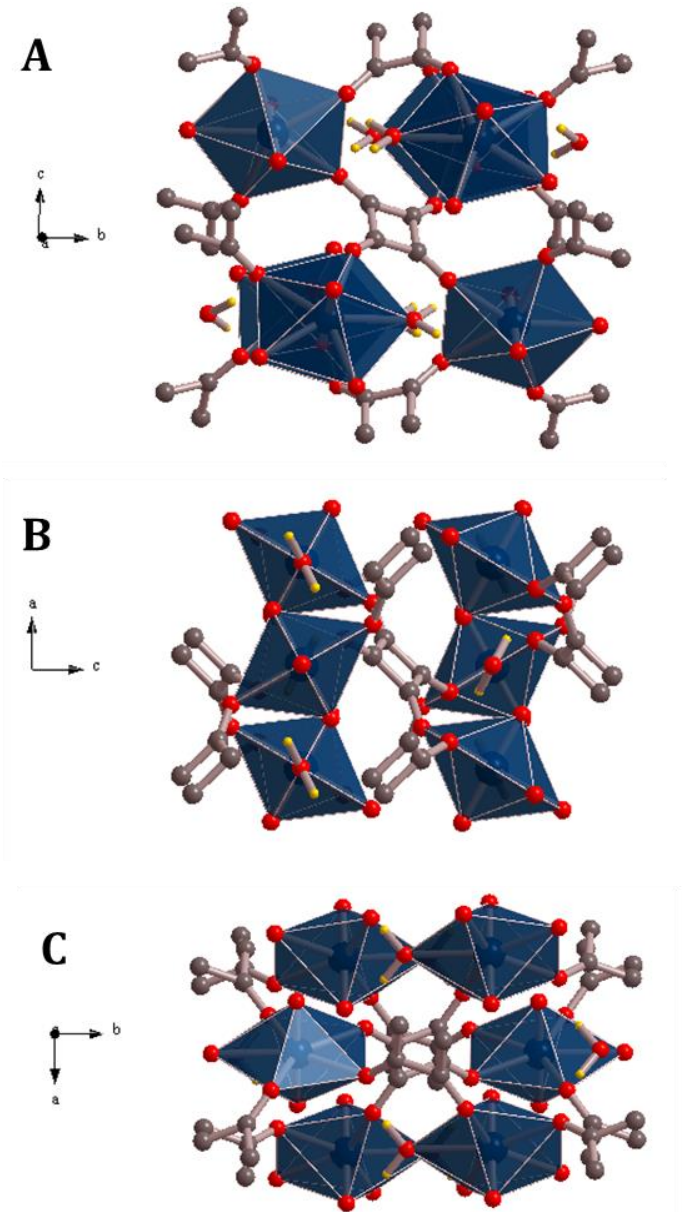

Figure 1. Calculated unit cell structure of USM; A) View of the unit cell from [100]; B) View of the unit cell from [010]; C) View of the unit cell from [001]. Color code: U-blue; O-red; C-grey; H-yellow. 
Table 1. Lattice parameters, unit cell volume and density of USM.

\begin{tabular}{ccccccccc}
\hline Parameter & $\boldsymbol{a}(\boldsymbol{\AA})$ & $\boldsymbol{b}(\boldsymbol{\AA})$ & $\boldsymbol{c}(\boldsymbol{\AA})$ & $\boldsymbol{\alpha} \mathbf{( d e g )}$ & $\boldsymbol{\beta}(\mathbf{d e g})$ & $\boldsymbol{\gamma}(\mathbf{d e g})$ & Vol. $\left(\AA^{\mathbf{3}}\right)$ & Dens. $\left(\mathbf{g} \cdot \mathbf{c m}^{-3}\right)$ \\
\hline DFT & 5.7763 & 11.3905 & 10.5534 & 90 & 90 & 90 & 694.36 & 3.827 \\
DFT+U & 5.7770 & 11.3860 & 10.5563 & 90 & 90 & 90 & 694.36 & 3.827 \\
Exp. [41] & 5.676 & 11.289 & 10.536 & 90 & 90 & 90 & 675.11 & 3.936 \\
\hline
\end{tabular}

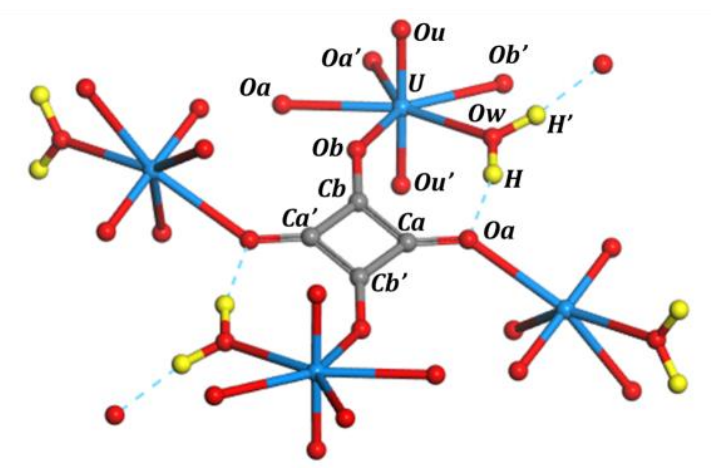

Figure 2. Detailed view of the bond structure in USM. Color code: U-blue; O-red; C-grey; H-yellow.

Since it was not possible to determine the hydrogen atom positions from X-ray diffraction experiments [41], they were determined theoretically. The final calculated atomic positions are given in an independent file of CIF (Crystallographic Information File) type. The resulting hydrogen bond structure of USM is displayed in Fig. 2.

The calculated bond distances and angles in USM are given in Table 2 and Table 3, in which they are compared with the corresponding experimental values from Wilson [41]. The atom labelling convention used in these tables is shown in Fig. 2. As can be appreciated, the agreement is very satisfactory. The $\mathrm{C}-\mathrm{C}$ bond distances in USM are intermediate between those commonly associated to single and double $\mathrm{C}-\mathrm{C}$ bonds.

\subsection{X-ray powder diffraction pattern of USM}

The X-ray powder diffraction pattern for USM was determined from the experimental [41] and computed structures [70] with $\mathrm{CuK}_{\alpha}$ radiation $(\lambda=1.540598 \AA)$, employing the REFLEX module of Materials Studio [54]. As can be observed in Fig. 3, the calculated (DFT) pattern is in excellent agreement with the experimental one. A detailed comparison of the line positions and intensities of the main reflections is given in Table 4. A detailed discussion of the variation of the X-ray powder diffraction pattern as a function of applied external pressures is given in Section 3.3.4.b.

\subsection{Mechanical properties}

\subsubsection{Mechanical stability}

Materials with orthorhombic unit cells have 9 nondegenerate elastic constants in the symmetric stiffness $C$ matrix [72,84]. The computed values of these constants for USM are given in Table 5. In this table, the standard Voigt notation for the indices of the stiffness matrix elements, $C_{i j}$, is used [72]. For orthorhombic systems a set of necessary and sufficient conditions for mechanical stability are known [84,89]. These conditions were adequately fulfilled by the computed stiffness tensor. Besides, the satisfaction of the dynamical stability conditions of the structure was also studied from phonon calculations. A structure is dynamically stable if and only all its phonon modes have positive frequencies for all wave vectors [89]. Therefore, the crystal structure of USM is mechanically and dynamically stable. The calculated phonon density of states is shown in Fig. 4.

Table 2. Bond distances in USM (in $\AA$ ).

\begin{tabular}{cccc}
\hline Bond & Exp. [41] & DFT & DFT+U \\
\hline \multicolumn{4}{c}{ U-O } \\
\hline $\mathrm{U}-\mathrm{Ou}$ & 1.695 & 1.774 & 1.774 \\
$\mathrm{U}-\mathrm{Ob}$ & 2.380 & 2.356 & 2.356 \\
$\mathrm{U}-\mathrm{Oa}$ & 2.445 & 2.440 & 2.439 \\
$\mathrm{U}-\mathrm{O} w$ & 2.462 & 2.454 & 2.453 \\
$\langle\mathrm{U}-\mathrm{O}(\mathrm{eq})\rangle$ & 2.42 & 2.41 & 2.41 \\
\hline \multicolumn{4}{c}{$\mathrm{C}-\mathrm{C}$} \\
$\mathrm{Ca}-\mathrm{Cb}$ & 1.392 & 1.472 & 1.472 \\
$\mathrm{Ca}-\mathrm{Cb}$ & 1.417 & 1.473 & 1.473 \\
$\langle\mathrm{C}-\mathrm{C}\rangle$ & 1.40 & 1.47 & 1.47 \\
\hline \multicolumn{4}{c}{$\mathrm{C}-\mathrm{O}$} \\
$\mathrm{Ca}-\mathrm{Oa}$ & 1.248 & 1.262 & 1.262 \\
$\mathrm{Cb}-\mathrm{Ob}$ & 1.272 & 1.254 & 1.254 \\
$\langle\mathrm{C}-\mathrm{O}\rangle$ & 1.26 & 1.26 & 1.26 \\
\hline \multicolumn{4}{c}{ Water and hydrogen-bond } \\
\hline $\mathrm{Ow}-\mathrm{H}$ & - & 0.988 & 0.987 \\
$\mathrm{H} \cdots \mathrm{Oa}$ & - & 1.751 & 1.752 \\
$\mathrm{Ow}--\mathrm{Oa}$ & 2.697 & 2.721 & 2.722 \\
\hline
\end{tabular}

Table 3. Bond angles in USM (in deg).

\begin{tabular}{|c|c|c|c|}
\hline Angle & Exp. [41] & DFT & DFT+U \\
\hline \multicolumn{4}{|c|}{ O-U-O } \\
\hline Ou-U-Ou' & 179.01 & 178.05 & 178.06 \\
\hline Ob-U-Ow & 71.15 & 71.72 & 71.73 \\
\hline Ob-U-Oa & 74.34 & 74.07 & 74.03 \\
\hline Oa-U-Oa' & 69.02 & 68.43 & 68.47 \\
\hline Ou-U-Ow & 90.50 & 90.98 & 90.97 \\
\hline $\mathrm{Ou}-\mathrm{U}-\mathrm{Ob}$ & 91.37 & 91.92 & 91.90 \\
\hline $\mathrm{Ou}-\mathrm{U}-\mathrm{Oa}$ & 88.22 & 87.68 & 87.69 \\
\hline Ou-U-Oa' & 90.97 & 90.70 & 90.70 \\
\hline Ou-U-Ob' & 88.95 & 88.69 & 88.71 \\
\hline \multicolumn{4}{|c|}{ O-C-C } \\
\hline $\mathrm{Oa}-\mathrm{Ca}-\mathrm{Cb}$ & 137.84 & 138.06 & 138.08 \\
\hline $\mathrm{Oa}-\mathrm{Ca}-\mathrm{Cb}$ & 130.95 & 131.58 & 131.55 \\
\hline $\mathrm{Ob}-\mathrm{Cb}-\mathrm{Ca}$ & 134.06 & 133.92 & 133.92 \\
\hline $\mathrm{Ob}-\mathrm{Cb}-\mathrm{Ca}$ & 135.91 & 136.44 & 136.46 \\
\hline \multicolumn{4}{|c|}{ C-C-C } \\
\hline $\mathrm{Ca}-\mathrm{Cb}-\mathrm{Ca}{ }^{\prime}$ & 89.47 & 89.64 & 89.62 \\
\hline $\mathrm{Cb}-\mathrm{Ca}-\mathrm{Cb}$ & 90.53 & 90.36 & 90.38 \\
\hline \multicolumn{4}{|c|}{ Water and hydrogen bond } \\
\hline H-Ow-H' & - & 109.71 & 109.76 \\
\hline $\mathrm{Ow}-\mathrm{H} \cdots \mathrm{Oa}$ & - & 166.41 & 166.48 \\
\hline
\end{tabular}




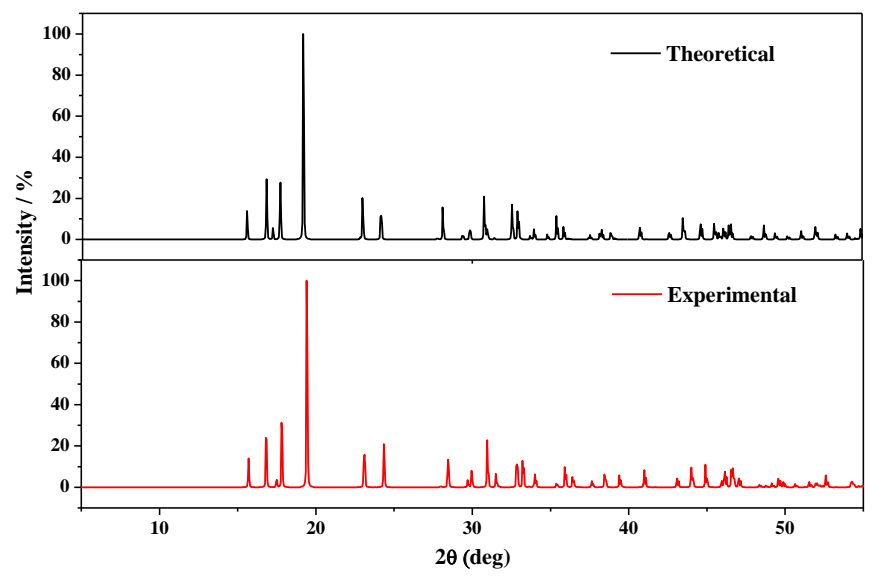

Figure 3. X-ray powder patterns of USM determined from the calculated and experimental [41] geometries.

Table 4. Main reflections in the X-Ray powder pattern of USM: a) X-Ray powder pattern computed from experimental geometry [41]; b) XRay powder diffractogram computed from calculated geometry.

\begin{tabular}{ccccccc}
\hline \multicolumn{4}{c}{ Experimental [41] } & \multicolumn{3}{c}{ Calculated } \\
\hline $\mathbf{2 \theta}(\mathbf{d e g})$ & $\mathbf{d}(\mathbf{\AA})$ & Int. $(\boldsymbol{\%})$ & {$[\mathbf{h k l}]$} & $\mathbf{2 \theta}(\mathbf{d e g})$ & $\mathbf{d}[\AA \mathbf{A}]$ & Int. $(\boldsymbol{\%})$ \\
\hline 15.687 & 5.6445 & 12.561 & {$[020]$} & 15.553 & 5.6930 & 12.432 \\
16.816 & 5.2680 & 28.898 & {$[002]$} & 16.784 & 5.2782 & 29.926 \\
17.813 & 4.9755 & 33.206 & {$[021]$} & 17.686 & 5.0108 & 32.921 \\
19.410 & 4.5694 & 100.00 & {$[111]$} & 19.154 & 4.6299 & 100.00 \\
23.075 & 3.8513 & 23.570 & {$[022]$} & 22.959 & 3.8706 & 21.717 \\
24.343 & 3.6534 & 19.798 & {$[112]$} & 24.120 & 3.6867 & 21.263 \\
28.435 & 3.1364 & 16.364 & {$[130]$} & 28.109 & 3.1720 & 16.206 \\
30.948 & 2.8872 & 22.008 & {$[113]$} & 30.746 & 2.9057 & 22.198 \\
32.826 & 2.7261 & 19.544 & {$[041]$} & 32.554 & 2.7483 & 19.806 \\
33.218 & 2.6949 & 17.184 & {$[132]$} & 32.917 & 2.7188 & 17.980 \\
35.914 & 2.4985 & 11.943 & {$[202]$} & 35.396 & 2.5339 & 12.781 \\
40.992 & 2.1999 & 9.417 & {$[043]$} & 40.739 & 2.2131 & 9.141 \\
44.012 & 2.0558 & 9.243 & {$[223]$} & 43.506 & 2.0785 & 10.236 \\
44.902 & 2.0170 & 12.134 & {$[134]$} & 44.629 & 2.0287 & 12.325 \\
46.134 & 1.9660 & 10.859 & {$[241]$} & 45.521 & 1.9911 & 11.155 \\
46.559 & 1.9490 & 9.721 & {$[152]$} & 46.132 & 1.9661 & 9.093 \\
46.639 & 1.9459 & 8.751 & {$[115]$} & 46.445 & 1.9536 & 8.656 \\
52.594 & 1.7387 & 7.201 & {$[243]$} & 52.015 & 1.7567 & 7.645 \\
\hline
\end{tabular}

Table 5. The nine non-vanishing elastic constants of USM. All values are given in units of GPa.

\begin{tabular}{ccccccccc}
\hline $\boldsymbol{C}_{\mathbf{1 1}}$ & $\boldsymbol{C}_{\mathbf{2 2}}$ & $\boldsymbol{C}_{\mathbf{3 3}}$ & $\boldsymbol{C}_{\mathbf{4 4}}$ & $\boldsymbol{C}_{\mathbf{5 5}}$ & $\boldsymbol{C}_{\mathbf{6 6}}$ & $\boldsymbol{C}_{\mathbf{1 2}}$ & $\boldsymbol{C}_{\mathbf{1 3}}$ & $\boldsymbol{C}_{\mathbf{2 3}}$ \\
\hline 43.68 & 75.55 & 34.34 & 25.03 & 34.83 & 16.09 & 26.75 & 29.87 & 17.25 \\
\hline
\end{tabular}

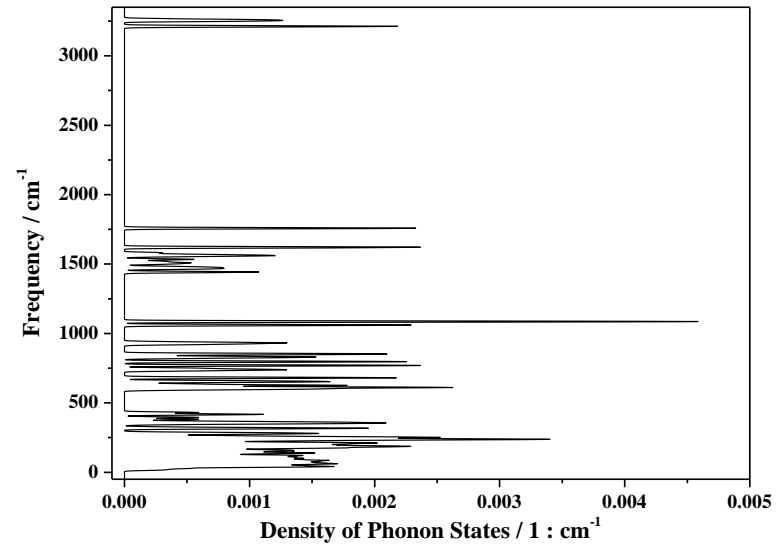

Figure 4. Calculated phonon density of states of USM. 


\subsubsection{Mechanical properties}

The mechanical properties of polycrystalline USM were determined according to the Voigt [90], Reuss [91], and Hill [92] schemes. The Voigt approach was chosen as the best one because it provided the best approximation to the bulk modulus computed from the equation of state (Section 3.3.3). The results obtained for the bulk, shear, and Young moduli and the Poisson ratio $(B, G, E$, and $v$, respectively) are given in Table 6. The ductility [93], hardness [94], and universal anisotropy [95] indices were also determined, being their values also reported in Table 6. USM is a brittle material because the ductility index, $D$, is smaller than $1.75[93,96]$. The computed Vickers hardness, $H$, was 3.6. This value corresponds to a material of intermediate hardness [94,57]. Finally, the computed universal anisotropy index, $A^{U}=3.6$, corresponds to a very anisotropic material [95]. This large anisotropy is the consequence of the large difference between the values of the elastic constants along the different directions and derives directly from the differences in bonding strength between the atoms belonging to the unit cell of USM in the different directions.

\subsubsection{Bulk modulus derivatives with respect to pressure}

The crystal structure of USM was optimized at eighteen different applied isotropic pressures. The computed volumes for the different pressures are plotted in Fig. 5. Then, the calculated pressure-volume data were fitted to a fourth-order Birch-Murnaghan equation of state [74] using the EOSFIT 5.2 program [75]. The fit produces the best possible values of the parameters in the EOS. These parameters include the bulk modulus and their first and second derivatives with respect to pressure at the temperature of $0 \mathrm{~K}$. The values found for $B$, $B^{\prime}$, and $B^{\prime \prime}$ were $B=36.70 \pm 0.57 \mathrm{GPa}, B^{\prime}=1.20 \pm 0.38$, and $B^{\prime \prime}=0.46 \pm 0.05 \mathrm{GPa}-1\left(\chi^{2}=0.002\right)$, respectively. The computed value of the single crystal bulk modulus is in good agreement with the polycrystalline bulk modulus obtained from the elastic constants in the Voigt approximation, $B=$ $33.48 \pm 1.31 \mathrm{GPa}$.

Table 6. Computed bulk modulus, shear modulus, Young modulus, Poisson ratio, Pugh's ratio, Vickers hardness, and universal anisotropy index $\left(B, G, E, v, D, H\right.$, and $A^{U}$, respectively) of USM. The values of $B, G, E$ are given in GPa.

\begin{tabular}{ccc}
\hline & Property & Value \\
\hline $\boldsymbol{B}$ & Bulk modulus & 33.48 \\
$\boldsymbol{G}$ & Shear modulus & 20.50 \\
$\boldsymbol{E}$ & Young modulus & 51.08 \\
$\boldsymbol{v}$ & Poisson ratio & 0.25 \\
$\boldsymbol{D}$ & Ductility index & 1.63 \\
$\boldsymbol{H}$ & Hardness index & 3.60 \\
$\boldsymbol{A}^{\boldsymbol{U}}$ & Universal anisotropy index & 3.60 \\
\hline
\end{tabular}

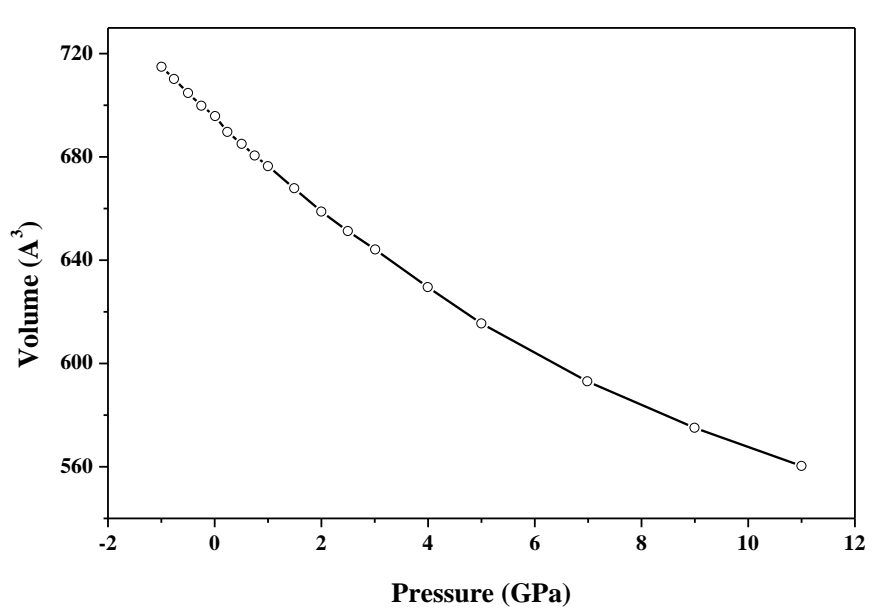

Figure 5. Unit cell volume of USM as a function of the applied isotropic pressure.

\subsubsection{Anomalous mechanical properties}

\subsection{4.a Negative Poisson ratio}

The Poisson ratio, $v$, is defined as the negative value of the ratio of the differential transverse and longitudinal strains, $v=$ $-\delta \epsilon_{\text {trans }} / \delta \epsilon_{\text {long }}$ resulting from the application of pressure directed along the longitudinal direction. The strain, $\epsilon_{i}$, is defined as the change of the solid size $\Delta L i$ along direction $i$ divided by the initial size $L i, \epsilon i=\Delta L i / L i$. The Poisson ratio is commonly positive because when a compressive pressure is applied to the solid along a certain direction, a contraction along the longitudinal direction and an extension along all the transverse directions is usually found. However, the Poisson ratio can have any value between minus and plus infinite and, in fact, some materials exhibit anomalous negative values of $v$ for certain longitudinal and transverse directions [8-9]. These materials laterally expand when they are stretched or laterally shrink when compressed. They term auxetic was coined in 1991 [97] for NPR materials.

The visualization of the variation of the elastic properties with the strain orientation is, except for the case of isotropic materials, quite complicated. Tridimensional representations of the most important elastic properties for USM are displayed in Fig. 6, which were obtained using the ElAM software developed by Marmier et al. [98] For the case of the shear modulus and Poisson ratios, depending on two directions, Fig. 6.C and Fig. 6.D provide a representation of surface of maximum $G$ and $v$, respectively, that is, the surface formed with the maximum values of these properties for the given direction of the longitudinal strain and all possible transverse directions. The visualization of these maximum surfaces is very useful since they are commonly very similar for structurally related compounds [65-66]. They can be used in order to recognize shearing effects in the phase transformations occurring between several related materials $[85,65]$. However, whereas the surface of minimum Poisson ratio is quite variable even for related compounds, its 
observation is also very useful, since it reveals possible negative values of the Poisson ratio. The surface of minimum Poison ratio, displayed in Fig. 7, shows that USM is an NPR material with a value of the lowest Poisson ratio of $v_{\min }=-0.47$, the longitudinal and transverse directions being $U_{\min }^{L}=(0.0,-0.83,0.55)$ and $U_{\min }^{T}=\left(\begin{array}{lll}0.0, & 0.55,0.83\end{array}\right)$, respectively.

\subsection{4.b Negative linear compressibility}

The structure of this material under the effect of different pressures applied along the direction of the minimum Poisson ratio was optimized to analyze the structural variations produced by the application of pressure. The lattice parameters and volumes obtained for twelve different applied pressures along this direction are reported in Table 7. The calculated unit cell volumes for positive applied pressures are displayed in Fig. 8. According to this figure, the unit cell volume increases under the application of positive pressures, from $0.025 \mathrm{GPa}$ to $0.094 \mathrm{GPa}$. Consequently, USM exhibits the negative linear compressibility (NLC) phenomenon in this pressure range. For pressures larger than $0.094 \mathrm{GPa}$, the volume begins to decrease and, therefore the NLC disappears.

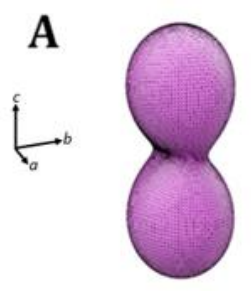

C

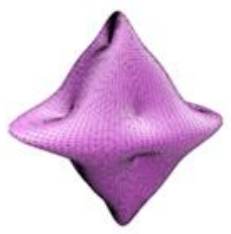

B

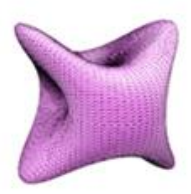

D

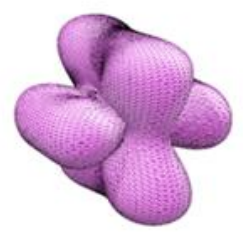

Figure 6. Elastic properties of USM as a function of the orientation of the applied strain: (A) Compressibility; (B) Young modulus; (C) Maximum shear modulus; (D) Maximum Poisson ratio.
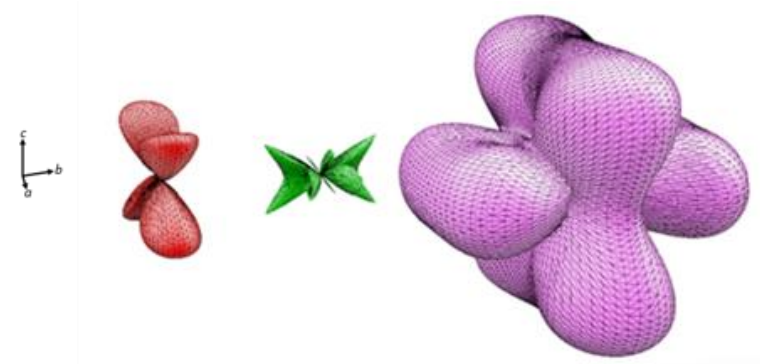

Figure 7. Computed surfaces of minimum (red), average (green), and maximum (violet) Poisson ratio of USM.
Table 7. Computed lattice parameters and volumes of USM unit cell at different applied pressures directed along $U_{\min }^{L}$.

\begin{tabular}{ccccc}
\hline $\mathbf{P}(\mathbf{G P a})$ & $\boldsymbol{a}(\mathbf{\AA})$ & $\boldsymbol{b}(\mathbf{\AA})$ & $\boldsymbol{c}(\mathbf{\AA})$ & $\mathbf{V o l} .\left(\mathbf{\AA}^{\mathbf{3}}\right)$ \\
\hline-0.070 & 5.8454 & 11.5787 & 10.2880 & 696.3074 \\
-0.045 & 5.8168 & 11.4985 & 10.4037 & 695.8532 \\
-0.017 & 5.7812 & 11.4307 & 10.5167 & 694.9767 \\
0.0 & 5.7763 & 11.3905 & 10.5534 & 694.3576 \\
0.029 & 5.7578 & 11.3461 & 10.6400 & 695.0974 \\
0.046 & 5.7383 & 11.2992 & 10.7339 & 695.9669 \\
0.075 & 5.7183 & 11.2479 & 10.8248 & 696.2401 \\
0.095 & 5.6859 & 11.2051 & 10.9301 & 696.3755 \\
0.139 & 5.6474 & 11.0954 & 11.1104 & 696.1792 \\
0.191 & 5.6131 & 10.9822 & 11.2774 & 695.1903 \\
0.224 & 5.6054 & 10.8389 & 11.4238 & 694.0724 \\
0.275 & 5.5875 & 10.7220 & 11.5602 & 692.5624 \\
\hline
\end{tabular}

The corresponding X-ray powder diffraction patterns as a function of pressure were determined from the optimized structures, being six of these patterns displayed in Fig. 9. The displacements of the main reflections in the X-Ray powder diffraction pattern due to the effect of the applied pressures are reported in Table 8.

The parameter $d$ of the main [111] and other reflections decrease (or, equivalently, the corresponding $2 \theta$ values increase), as expected from the increase of the applied external pressure. The [020] reflection, which is the one with largest negative variation, maps the decrease of $b$ lattice parameter. The [200] reflection, mapping the decrease of $a$ lattice parameter, also decreases but to a much smaller extent. There are also many reflections which displace towards larger $d$. The reflection of largest positive increase is [002] which maps directly the increase of $c$ lattice parameter.

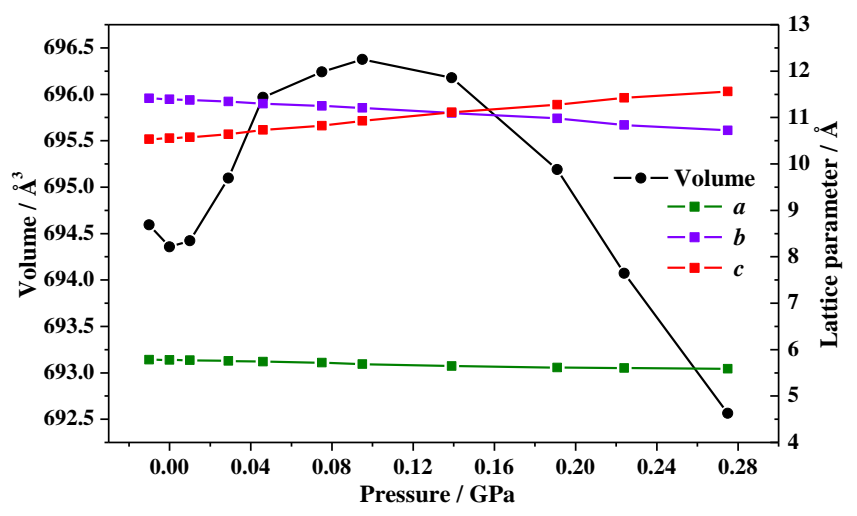

Figure 8. Calculated lattice parameters and unit cell volumes of USM as a function of positive applied pressures directed along $U_{\text {min }}^{L}$. 


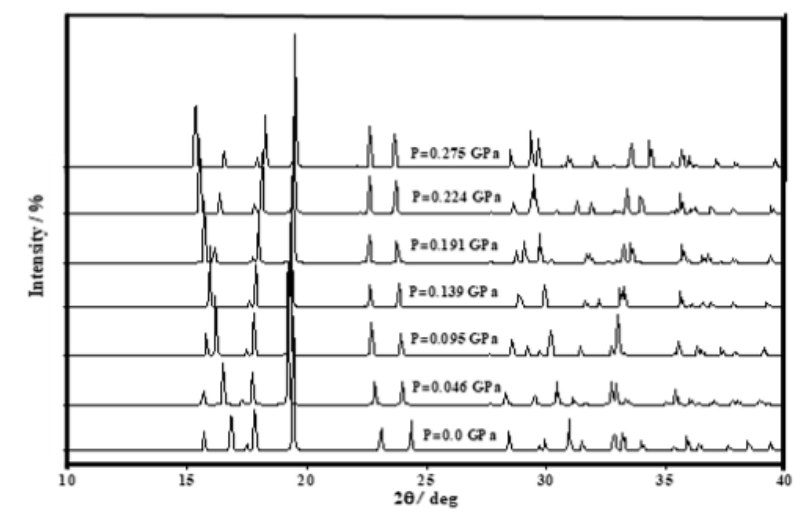

Figure 9. X-ray powder diffraction pattern of USM as a function of the applied pressures in the direction of minimum Poisson ratio.

Table 8. Displacement of some of the most intense reflections in the X-ray powder diffraction pattern of USM resulting from the application of pressure. The $2 \theta$ and $d$ values associated to the X-ray powder diffraction pattern of USM at zero pressure are also given. The values of $2 \theta$ and $d$ associated with each reflection [hkl] are given in degrees and $\AA$, respectively. The pressure intervals are given in GPa.

\begin{tabular}{ccccccccc}
\hline$[\mathbf{h k 1}]$ & $\mathbf{2} \boldsymbol{\theta} \mathbf{( 0 )}$ & $\boldsymbol{d}(\mathbf{0})$ & $\Delta(\mathbf{0 . 0 - 0 . 0 4 6})$ & $\Delta(\mathbf{0 . 0 4 6 - 0 . 0 9 5})$ & $\Delta(\mathbf{0 . 0 9 5 - 0 . 1 3 9})$ & $\Delta(\mathbf{0 . 1 3 9 - 0 . 1 9 1})$ & $\Delta(\mathbf{0 . 1 9 1 - 0 . 2 2 4})$ & $\Delta(\mathbf{0 . 2 2 4 - 0 . 2 7 5})$ \\
\hline$[111]$ & 19.154 & 4.630 & -0.011 & -0.019 & -0.015 & -0.015 & -0.006 & -0.010 \\
{$[021]$} & 17.686 & 5.011 & -0.011 & -0.014 & -0.022 & -0.026 & -0.039 & -0.033 \\
{$[002]$} & 16.784 & 5.278 & 0.089 & 0.098 & 0.090 & 0.083 & 0.073 & 0.068 \\
{$[113]$} & 30.746 & 2.906 & 0.026 & 0.027 & 0.024 & 0.021 & 0.020 & 0.017 \\
{$[022]$} & 22.959 & 3.871 & 0.020 & 0.021 & 0.013 & 0.008 & -0.004 & 0.002 \\
{$[112]$} & 24.120 & 3.687 & 0.016 & 0.014 & 0.013 & 0.010 & 0.014 & 0.009 \\
{$[041]$} & 32.554 & 2.748 & -0.017 & -0.018 & -0.022 & -0.024 & -0.031 & -0.025 \\
{$[132]$} & 32.917 & 2.719 & -0.003 & -0.005 & -0.008 & -0.009 & -0.013 & -0.010 \\
{$[130]$} & 28.109 & 3.172 & -0.023 & -0.027 & -0.028 & -0.028 & -0.030 & -0.026 \\
{$[202]$} & 35.396 & 2.534 & -0.004 & -0.008 & -0.005 & -0.005 & 0.004 & -0.001 \\
{$[020]$} & 15.553 & 5.693 & -0.043 & -0.047 & -0.055 & -0.057 & -0.072 & -0.058 \\
{$[134]$} & 44.629 & 2.029 & 0.014 & 0.014 & 0.011 & 0.008 & 0.006 & 0.005 \\
{$[241]$} & 45.521 & 1.991 & -0.013 & -0.015 & -0.015 & -0.015 & -0.013 & -0.013 \\
{$[223]$} & 43.506 & 2.079 & 0.002 & 0.000 & 0.000 & 0.000 & 0.003 & 0.000 \\
{$[043]$} & 40.739 & 2.213 & 0.004 & 0.004 & 0.000 & -0.003 & -0.009 & -0.007 \\
{$[152]$} & 46.132 & 1.966 & -0.008 & -0.010 & -0.012 & -0.013 & -0.017 & -0.014 \\
{$[115]$} & 46.445 & 1.954 & 0.026 & 0.028 & 0.025 & 0.023 & 0.020 & 0.019 \\
{$[243]$} & 52.015 & 1.757 & -0.002 & -0.004 & -0.005 & -0.006 & -0.006 & -0.006 \\
{$[200]$} & 30.933 & 2.889 & -0.019 & -0.026 & -0.019 & -0.017 & -0.004 & -0.009 \\
{$[004]$} & 33.941 & 2.639 & 0.044 & 0.049 & 0.045 & 0.042 & 0.037 & 0.034 \\
{$[204]$} & 46.577 & 1.948 & 0.012 & 0.010 & 0.010 & 0.009 & 0.011 & 0.008 \\
{$[023]$} & 29.826 & 2.993 & 0.030 & 0.031 & 0.026 & 0.022 & 0.015 & 0.013 \\
\hline
\end{tabular}

\subsection{4.c Negative linear compressibility in one direction}

The overall bulk modulus (or its inverse, the compressibility) is required to be positive for thermodynamic and mechanical stability [8]. A material submitted to a hydrostatic (isotropic) pressure cannot increase its volume, unless it is unstable. Negative linear compressibility is not related to unstable materials and refer to a positive variation of the volume when the material is submitted to a uniform compression directed along a given direction and also to the increase of one or two single directions of the unit cell of a material under the aplication of an hydrostatic pressure [1012]. In the first case the derivative of the volume with respect to pressure is negative. In the second case, the volume does not increase and the positive variation of the parameters in some directions is compensated by a larger negative variation of the paramters in the remaining directions.
USM also displays NLC under the effect of isotropic pressures since in this case the $b$ lattice parameter increases for low pressures from 0.091 to $0.196 \mathrm{GPa}$ as shown in the inset of Figure 10 and in Table 9.

\section{Discussion}

The values of selected bond distances and angles between the atoms in the structure of USM for 6 different external positive pressures applied in the direction of minimum Poisson ratio are provided in Table 10. As can be seen, the structure of the carbon four-membered ring remains almost unaltered as a consequence of the application of pressure in the $U_{\min }^{L}$ direction. The same is true for the water molecule structure and hydrogen bond geometry. The unique significant change observed is the variation of the shape of the uranium coordination polyhedra. 


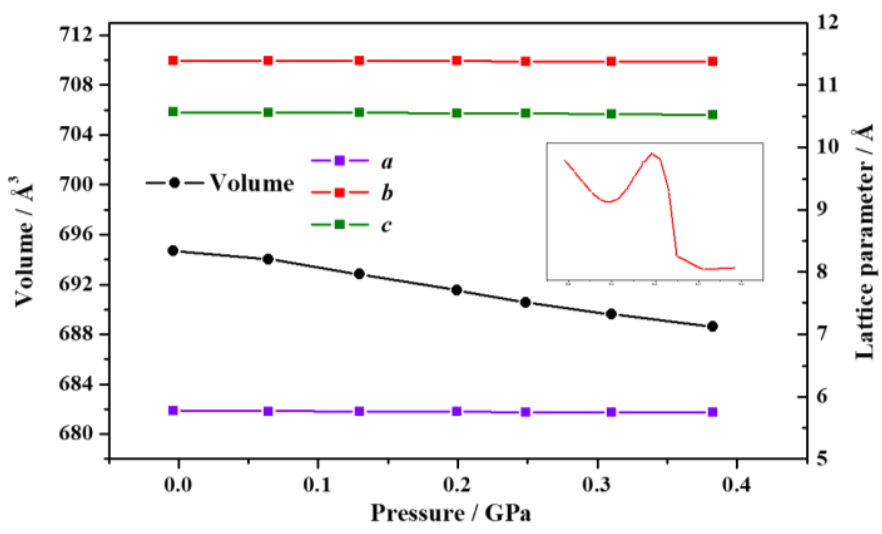

Figure 10. Calculated lattice parameters and unit cell volumes of USM as a function of positive applied isotropic pressures. The variation of $b$ lattice paramter with pressure is shown in a smaller vertical scale in the inset of the Figure.

Table 9. Computed lattice parameters of USM unit cell at different applied isotropic pressures.

\begin{tabular}{cccc}
\hline $\mathbf{P}(\mathbf{G P a})$ & $\boldsymbol{a}(\mathbf{\AA})$ & $\boldsymbol{b}(\mathbf{\AA})$ & $\boldsymbol{c}(\AA)$ \\
\hline-0.004 & 5.7742 & 11.3894 & 10.5631 \\
0.065 & 5.7727 & 11.3852 & 10.5600 \\
0.130 & 5.7650 & 11.3859 & 10.5550 \\
0.199 & 5.7578 & 11.3906 & 10.5444 \\
0.249 & 5.7564 & 11.3780 & 10.5434 \\
0.310 & 5.7536 & 11.3763 & 10.5359 \\
0.383 & 5.7509 & 11.3765 & 10.5253 \\
\hline
\end{tabular}

Table 10. Selected bond distances (in $\AA$ ) and angles (in degree) in USM at different applied pressures directed along the direction of minimum Poisson ratio.

\begin{tabular}{|c|c|c|c|c|c|c|c|}
\hline $\mathbf{P}(\mathbf{G P a})$ & 0.0 & 0.046 & 0.095 & 0.139 & 0.191 & 0.224 & 0.275 \\
\hline \multicolumn{8}{|c|}{ U-O } \\
\hline $\mathrm{U}-\mathrm{Ou}$ & 1.774 & 1.774 & 1.774 & 1.774 & 1.774 & 1.774 & 1.774 \\
\hline $\mathrm{U}-\mathrm{Ob}$ & 2.356 & 2.364 & 2.372 & 2.381 & 2.393 & 2.402 & 2.415 \\
\hline U-Oa & 2.440 & 2.431 & 2.422 & 2.414 & 2.405 & 2.396 & 2.389 \\
\hline $\mathrm{U}-\mathrm{Ow}$ & 2.454 & 2.443 & 2.430 & 2.420 & 2.409 & 2.404 & 2.393 \\
\hline \multicolumn{8}{|c|}{ O-U-O } \\
\hline Ou-U-Ou' & 178.05 & 177.97 & 178.13 & 178.01 & 178.18 & 178.30 & 178.40 \\
\hline Ob-U-Ow & 71.72 & 72.30 & 72.76 & 73.33 & 73.84 & 74.54 & 75.06 \\
\hline Ob-U-Oa & 74.07 & 73.34 & 72.71 & 72.04 & 71.43 & 70.64 & 70.03 \\
\hline Oa-U-Oa' & 68.43 & 68.71 & 69.06 & 69.27 & 69.48 & 69.74 & 69.88 \\
\hline \multicolumn{8}{|c|}{ C-C } \\
\hline $\mathrm{Ca}-\mathrm{Cb}$ & 1.472 & 1.471 & 1.470 & 1.470 & 1.469 & 1.468 & 1.467 \\
\hline $\mathrm{Ca}-\mathrm{Cb}$ ' & 1.473 & 1.474 & 1.475 & 1.476 & 1.477 & 1.479 & 1.480 \\
\hline \multicolumn{8}{|c|}{ C-O } \\
\hline $\mathrm{Ca}-\mathrm{Oa}$ & 1.262 & 1.262 & 1.262 & 1.262 & 1.262 & 1.261 & 1.261 \\
\hline $\mathrm{Cb}-\mathrm{Ob}$ & 1.254 & 1.253 & 1.253 & 1.253 & 1.253 & 1.253 & 1.253 \\
\hline \multicolumn{8}{|c|}{ Water and hydrogen-bond } \\
\hline $\mathrm{Ow}-\mathrm{H}$ & 0.988 & 0.988 & 0.988 & 0.988 & 0.987 & 0.986 & 0.986 \\
\hline $\mathrm{H} \cdots \mathrm{Oa}$ & 1.751 & 1.746 & 1.748 & 1.745 & 1.749 & 1.764 & 1.765 \\
\hline Ow---Oa & 2.721 & 2.716 & 2.717 & 2.712 & 2.712 & 2.721 & 2.718 \\
\hline
\end{tabular}




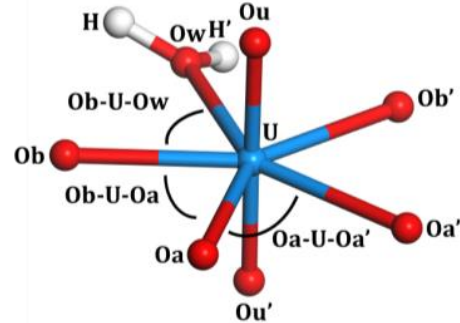

Figure 11. Detailed picture of a uranyl pentagonal bipyramid in the crystal structure of USM. The picture shows the atom labelling convention used and the meaning of the interatomic angles $\mathrm{Ob}-\mathrm{U}$ Ow, Ob-U-Oa, and Oa-U-Oa'.

In the pentagonal bipyramids, while the apical oxygens remain at nearly the same positions, the structure of the equatorial pentagon changes very significantly. Thus, the U$\mathrm{Oa}$ and U-Ow distances decrease a large amount as result of the application of the external pressure and the $\mathrm{U}-\mathrm{Ob}$ distance increases. Besides, the $\mathrm{Ob}-\mathrm{U}-\mathrm{Oa}$ angle decreases and the $\mathrm{Ob}-$ $\mathrm{U}-\mathrm{O} w$ and the Oa-U-Oa' increase. The decrease of the U-Oa and $\mathrm{U}-\mathrm{Ow}$ bond distances is the most important reason for the decrease of the a and $b$ lattice parameters. Similarly, the increase of the $\mathrm{U}-\mathrm{Ob}$ distance is the major responsible of the increase of $\mathrm{c}$ lattice parameter. The precise meaning of these bond distances and angles is shown very clearly in Fig. 11.For a given external pressure applied in the direction of the minimum Poison ratio, a decrease of the distance along this direction and an increase of the distances along the two perpendicular directions is expected. However, for USM, the unique significant change in the crystal structure is the variation of the shape of the uranium coordination polyhedra which leads to a decrease of the distance along the transverse direction leading to NPR values. Besides, for the range of pressures going from $0.025 \mathrm{GPa}$ to $0.094 \mathrm{GPa}$, the large increase of the $c$ lattice parameter is not compensated by the decrease of $a$ and $b$ parameters and the unit cell volume increases so that USM exhibits negative linear compressibility. In a similar way, for the case of the application of small hydrostatic pressures, the unique significant geometric variations observed are those within the uranyl pentagonal bipyramids.

Clearly, the mechanism for NLC in uranyl squarate monohydrate, as described above, is related to the change in shape of the uranyl polyhedra and unrelated to the wine-rack structural mechanism. Although non-topological mechanisms alternative to the wine-rack mechanism have been proposed [99-100], the case of USM is also different from these mechanisms.

\section{Conclusions}

The mechanical properties of the uranyl squarate monohydrate were studied using theoretical solid-state methods based in Density Functional Theory employing plane waves and pseudopotentials. Very demanding calculation parameters were utilized in order to obtain a realistic description of the mechanical behavior of this material. Since the determination of the positions of the hydrogen atoms in the unit cell of this material was not possible from X-ray diffraction data by structure refinement, they were determined theoretically. The computed lattice parameters, bond distances, angles, and $\mathrm{X}$-ray powder diffraction patterns of this material were in very good agreement with the experimental data.

This material was found to be mechanically and dynamically stable since the corresponding stability conditions were satisfied. The values of the bulk modulus and its pressure derivatives, shear and Young moduli, Poisson ratio, ductility, hardness, and mechanical anisotropy indices of this material were determined. This study has revealed that this material exhibits the important negative Poisson ratio and negative linear compressibility phenomena. Uranyl squarate monohydrate is a very anisotropic brittle material characterized by a bulk modulus of $\sim 33 \mathrm{GPa}$, which shows a minimum value of the NPR of the order of -0.5 .

Uranyl squarate monohydrate displays NLC values for a limited range of positive pressures, from $0.025 \mathrm{GPa}$ to 0.094 $\mathrm{GPa}$, applied along the direction of minimum negative Poisson ratio. The analysis of the crystal structure as a function of pressure demonstrates that the mechanism of NLC of this material is related to the change in shape of the uranyl pentagonal bipyramids and unrelated to the wine-rack structural mechanism.

\section{Supplementary Information}

The supplementary Information associated with this article contains the final calculated atomic positions in the unit cell of uranyl squarate monohydrare which are given in an independent file of CIF (Crystallographic Information File) type.

\section{Acknowledgements}

Supercomputer time by the CTI-CSIC center is greatly acknowledged. This work has been carried out in the context of a collaboration agreement between CSIC and CIEMAT: "Caracterización experimental y teórica de fases secundarias y óxidos de uranio formados en condiciones de almacenamiento de combustible nuclear". We also want to thank Dr. Ana María Fernández for reading the document and many helpful comments.

\section{References}

[1] West R (ed.) 1980 Oxocarbons (New York: Academic Press)

[2] West R, Niu N Y, Powell D L and Evans M V 1960 Symmetrical Resonance Stabilized Anions, $\mathrm{C}_{\mathrm{n}} \mathrm{O}_{\mathrm{n}}^{2-} J$. Am. Chem. Soc. 82, 6204-6205 
[3] Leibovici C 1972 Theoretical Analysis of the Structure of Monocyclic Oxocarbon Dianions $\left[C_{n} O_{n}\right]^{2-}(\mathrm{n}=3,4,5,6) J$. Mol. Struct. 13, 185-189

[4] Moyano A and Serratosa F 1982 A Simple Model for the Electronic Structure of Oxocarbon Dianions J. Mol. Struct. 90 , 131-136

[5] Seitz G and Imming P 1992 Oxocarbons and Pseudooxocarbons Chem. Rev. 92, 1227-1260

[6] Colmenero F 2018 Anomalous Mechanical Behavior of the Deltic, Squaric, and Croconic Acids Mater. Res. Express Under review

[7] Lakes R S 1987 Foam Structures with a Negative Poisson's Ratio Science 235, 1038-1040

[8] Lakes R S 2017 Negative-Poisson's-Ratio Materials: Auxetic Solids Annu. Rev. Mater. Res. 47, 63-81

[9] Greaves G N, Greer A L, Lakes R S, Rouxel T 2011 Poisson's Ratio and Modern Materials Nature Mater. 10, 823-837

[10] Baughman R H, Stafström S, Cui C and Dantas S O 1998 Materials with Negative Compressibilities in One or More Dimensions Science 279, 1522-1524

[11] Kornblatt J A, Sirota E B, King H E, Baughman R H and Cui C 1988 Materials with Negative Compressibilities Science 281, 143-143

[12] Cairns A B and Goodwin A L 2015 Negative Linear Compressibility Phys. Chem. Chem. Phys. 17, 20449-20465

[13] Colmenero F 2018 Revealing Rutherfordine Mineral as an Auxetic Material Appl. Sci. 8, 2281-2290

[14] Colmenero F 2018 Mechanical Properties of Anhydrous Oxalic Acid and Oxalic Acid Dihydrate Phys. Chem. Chem. Phys. Under review

[15] Keskar N R and Chelikowsky J R 1992 Negative Poisson's Ratios in Crystalline $\mathrm{SiO}_{2}$ from First-Principles Calculations Nature 358, 222-224

[16] Grima J N, Gatt R, Alderson A and Evans K E 2006 An Alternative Explanation for the Negative Poisson's Ratios in $\alpha$ Cristobalite Mater. Sci. Eng. A Struct. 423, 219-224

[17] Grima J N, Gatt R, Zammit V, Williams J J, Evans K E, Alderson A and Walton R I 2007 Natrolite: A Zeolite with Negative Poisson's Ratios J. Appl. Phys. 101, 086102

[18] Coudert F X 2016 Systematic Investigation of the Mechanical Properties of Pure Silica Zeolites: Stiffness, Anisotropy, and Negative Linear Compressibility Phys. Chem. Chem. Phys. 18 , 9079-9087

[19] Coudert F X 2017 Predicting the Mechanical Properties of Zeolite Frameworks by Machine Learning Chem. Mater. 29, 7833-7839

[20] Yao Y T, Alderson K L and Alderson A 2016 Modeling of Negative Poisson's Ratio (Auxetic) Crystalline Cellulose $I_{\beta}$ Cellulose 23, 3429-3448

[21] Tan J C, Civalleri B, Erba A and Albanese E 2015 Quantum Mechanical Predictions to Elucidate the Anisotropic Elastic Properties of Zeolitic Imidazolate Frameworks: ZIF-4 vs. ZIFzni CrystEngComm 17, 375-382

[22] Ryder M R and Tan J C 2016 Explaining the Mechanical Mechanisms of Zeolitic Metal-Organic Frameworks: Revealing Auxeticity and Anomalous Elasticity Dalton Trans. $45,4154-4161$
[23] Sun H, Mukherjee S and Singh C V 2016 Mechanical Properties of Monolayer Penta-Graphene and Phagraphene: A First-Principles Study Phys. Chem. Chem. Phys. 18, 2673626742

[24] Du Y, Maassen J, Wu W, Luo Z, Xu X and Ye P D 2016 Auxetic Black Phosphorus: A 2D Material with Negative Poisson's Ratio Nano Lett. 16, 6701-6708

[25] Li W, Probert M R, Kosa M, Bennett M T D, Thirumurugan A, Burwood R P, Parinello M, Howard J A and Cheetham A K 2012 Negative Linear Compressibility of a Metal-organic Framework J. Am. Chem. Soc. 134, 11940-11943

[26] Qiao Y, Wang K, Yuan H, Yang K and Zou B 2015 Negative Linear Compressibility in Organic Mineral Ammonium Oxalate Monohydrate with Hydrogen Bonding Wine-Rack Motifs J. Phys. Chem. Lett. 6, 2755-2760

[27] Coates C S, Makepeace J W, Seel A G, Baise M, Slater B, and Goodwin A L 2018 Synthesis, PtS-type Structure, and Anomalous Mechanics of the $\mathrm{Cd}(\mathrm{CN})_{2}$ Precursor $\mathrm{Cd}\left(\mathrm{NH}_{3}\right)_{2}\left[\mathrm{Cd}(\mathrm{CN})_{4}\right]$ Dalton Trans. 47, 7263-7271

[28] Marmier, A, Ntoahae, P S, Ngoepe P E, Pettifor D G and Parker S C 2010 Negative Compressibility in Platinum Sulfide Using Density-Functional Theory Phys. Rev. B 81, 172102

[29] Kang L, Jiang X, Luo S, Gong P, Li W, Wu X, Li Y, Li X, Chen $C$ and Lin Z 2016 Negative Linear Compressibility in a Crystal of $\alpha-\mathrm{BiB}_{3} \mathrm{O}_{6}$ Sci. Rep. 5, 13432; 7 pp

[30] Dagdelen J, Montoya J, De Jong M and Persson K 2017 Computational Prediction of New Auxetic Materials Nature Commun. 8, 323; 8 pp

[31] Ho D T, Park S D, Kwon S Y, Park K and Kim S Y 2014 Negative Poisson's Ratios in Metal Nanoplates Nature Commun. 5, 3255; 8 pp

[32] Wu D, Wang S, Zhan S, Yuan S J, Yang B and Chen H 2018 Highly Negative Poisson's Ratio in a Flexible TwoDimensional Tungsten Carbide Monolayer Phys. Chem. Chem. Phys. 20, 18924-18930

[33] Hao F, Liao X, Li M, Xiao H and Chen X 2018 OxidationInduced Negative Poisson's Ratio of Phosphorene J. Phys. Cond. Matter 30, 315302

[34] Wang H and Li Q, Gao Y, Miao F, Zhou X F and Wan X G 2016 Strain Effects on Borophene: Ideal Strength, Negative Possion's Ratio and Phonon Instability New J. Phys. 18, 073016

[35] Wang H, Zhang Z D, Wu R Q and Sun L Z 2013 Large-Scale First-Principles Determination of Anisotropic Mechanical Properties of Magnetostrictive Fe-Ga Alloys Acta Mater. 61, 2919-2925

[36] Wang H, Li X, Li P and Yang J 2017 -Phosphorene: a TwoDimensional Material with High Negative Poisson's Ratio Nanoscale 9, 850-855

[37] Wang X F, Jones T E, Li W and Zhou Y C 2012 Extreme Poisson's Ratios and their Electronic Origin in B2 CsCl-type AB Intermetallic Compounds Phys. Rev. B 85, 134108

[38] Yalameha S and Vaez A 2018 Ab-Initio Thermodynamic and Elastic Properties of AlNi and AlNi Intermetallic Compounds Int. J. Mod. Phys. B 32, 1850129

[39] Hsueh H C, Lee C C, Wang C W and Crain J 2000 Compression Mechanisms in the Anisotropically Bonded Elements Se and Te Phys. Rev. B 61, 3851-3856 
[40] Ren W, Ye J T, Shi W, Tang Z K, Chan C T and Sheng P 2009 Negative compressibility of Selenium chains confined in the channels of zeolite singe crystals New J. Phys. 11, 103014

[41] Wilson A S 1982 Unanyl-3,4-dioxocyclobutene-1,2-diolate Monohydrate Cryst. Struc. Commun. 11, 809-813

[42] Rowland C E and Cahill C L 2010 Hydrothermal Synthesis of Uranyl Squarates and Squarate-Oxalates: Hydrolysis Trends and In Situ Oxalate Formation Inorg. Chem. 49, 6716-6724

[43] Rowland C E and Cahill C L 2010 Capturing Hydrolysis Products in the Solid State: Effects of pH on Uranyl Squarates under Ambient Conditions Inorg. Chem. 49, 8668-8673

[44] Basile M, Unruh D K, Streicher L and Forbes T Z 2017 Spectral Analysis of the Uranyl Squarate and Croconate System: Evaluating Differences between the Solution and Solid-State Phases Cryst. Growth Des. 17, 5330-5341

[45] Cahill C L, de Lill D T and Frisch M 2007 Homo- and Heterometallic Coordination Polymers from the f Elements. Cryst. Eng. Commun. 9, 15-26

[46] Cantos P M, Popeb S J A and Cahill C L 2013 An Exploration of Homo- and Heterometallic $\mathrm{UO}_{2}^{2+}$ Hybrid Materials Containing Chelidamic Acid: Synthesis, Structure, and Luminescence Studies CrystEngComm. 15, 9039-9051

[47] Xie Y R, Zhao R H, Wang X S, Qu Z R, Xiong R G, Xue X, Xue Z and You X Z 2003 2D Chiral Uranyl(VI) Coordination Polymers with Second-Harmonic Generation Response and Ferroelectric Properties Eur. J. Inorg. Chem. 2003, 3712-3715

[48] Yu Z T, Li G H, Jiang Y S, Xu J J and Chen J S A 2003 Uranium-Zinc-Organic Molecular Compound Containing Planar Tetranuclear Uranyl Units Dalton Trans. 0, 4219-4220

[49] Chen W, Yuan H M, Wang J Y, Liu Z Y, Xu J J, Yang M and Chen J S 2003 Synthesis, Structure, and Photoelectronic Effects of a Uranium-Zinc-organic Coordination Polymer Containing Infinite Metal Oxide Sheets J. Am. Chem. Soc. 125, 9266-9267

[50] Yu Z T, Liao Z L, Jiang Y S, Li G H, Li G D and Chen J S 2004 Construction of a Microporous Inorganic-Organic Hybrid Compound with Uranyl Units Chem. Commun. 0, 1814-1815

[51] Perdew J P, Burke K and Ernzerhof M 1996 Generalized Gradient Approximation Made Simple Phys. Rev. Lett. 77 3865-3868

[52] Grimme S 2006 Semiempirical GGA-type Density Functional Constructed with a Long-Range Dispersion Correction $J$. Comput. Chem. 27, 1787-1799

[53] Clark S J, Segall M D, Pickard C J, Hasnip P J, Probert M I J, Refson K and Payne M C 2005 First Principles Methods Using CASTEP Z. Kristallogr. 220, 567-570

[54] MaterialsStudio, http://3dsbiovia.com/products/collaborativescience/biovia-materials-studio/ (accessed September 27, 2018)

[55] Troullier N and Martins J L 1991 Efficient Pseudopotentials for Plane-Wave Calculations Phys. Rev. B 43, 1993-2006

[56] Bonales L J, Colmenero F, Cobos J and Timón V 2016 Spectroscopic Raman Characterization of Rutherfordine: A Combined DFT and Experimental Study Phys. Chem. Chem. Phys. 18, 16575-16584

[57] Colmenero F 2017 Characterization of Secondary Phases of Spent Nuclear Fuel under Final Geological Disposal Conditions: Experimental and Theoretical Studies, Ph. D. Thesis (Madrid: Universidad Autónoma de Madrid)
[58] Colmenero F, Bonales L J, Cobos J and Timón V 2017 Study of the Thermal Stability of Studtite by In Situ Raman Spectroscopy and DFT Calculations Spectrochim. Acta. A 174, 245-253

[59] Colmenero F, Bonales L J, Cobos J and Timón V 2017 Structural, Mechanical and Vibrational Study of Uranyl Silicate Mineral Soddyite by DFT Calculations J. Solid. State Chem. 253, 249-257

[60] Colmenero F, Bonales L J, Cobos J and Timón V 2017 Thermodynamic and Mechanical Properties of Rutherfordine Mineral Based on Density Functional Theory J. Phys. Chem. C 121, 5994-6001

[61] Colmenero F, Bonales L J, Cobos J and Timón V 2017 Density Functional Theory Study of the Thermodynamic and Raman Vibrational Properties of $\gamma-\mathrm{UO}_{3}$ Polymorph J. Phys. Chem. C 121, 14507-14516

[62] Colmenero F, Bonales L J, Timón V and Cobos J 2018 Structural, Mechanical, and Raman Spectroscopic Characterization of Layered Uranyl Silicate Mineral Uranophane- $\alpha$ by DFT Methods Clay Miner. DOI: 10.1180/clm.2018.27

[63] Colmenero F, Fernández A M, Cobos J and Timón, V 2018 Thermodynamic Properties of Uranyl Containing Materials Based on Density Functional Theory J. Phys. Chem. C 122, 5254-5267

[64] Colmenero F, Fernández A M, Cobos J and Timón V 2018 Temperature Dependent Free Energies of Reaction of Uranyl Containing Materials Based on Density Functional Theory $J$. Phys. Chem. C 122, 5268-5279

[65] Colmenero F, Cobos J and Timón V. Periodic Density Functional Theory Study of the Structure, Raman Spectrum and Mechanical Properties of Schoepite Mineral Inorg. Chem. $57,4470-4481$

[66] Colmenero F, Fernández A M, Cobos J and Timón V 2018 Becquerelite Mineral Phase: Crystal Structure and Thermodynamic and Mechanic Stability by Using Periodic DFT RSC Adv. 8, 24599-24616

[67] Payne M C, Teter M P, Ailan D C, Arias A and Joannopoulos J D 1992 Iterative Minimization Techniques for Ab Initio Total-Energy Calculations: Molecular Dynamics and Conjugate Gradients Rev. Mod. Phys. 64, 1045-1097

[68] Pfrommer B G, Cote M, Louie S G and Cohen M L 1997 Relaxation of Crystals with the Quasi-Newton Method $J$. Comput. Phys. 131, 233-240

[69] Monkhorst H J and Pack J D 1976 Special Points for Brillouinzone Integration Phys. Rev. B 13, 5188-5192

[70] Downs R T, Bartelmehs K L, Gibbs G V and Boisen M B 1993 Interactive Software for Calculating and Displaying X-Ray or Neutron Powder Diffractometer Patterns of Crystalline Materials Am. Mineral. 78, 1104-1107

[71] Yu R, Zhu J and Ye H Q 2010 Calculations of Single-Crystal Elastic Constants Made Simple Comput. Phys. Commun. 181, 671-675

[72] Nye J F 1976 Physical Properties of Crystals (Oxford: Clarendon)

[73] Baroni S, de Gironcoli S and Dal Corso A 2001 Phonons and Related Crystal Properties from Density-Functional Perturbation Theory Rev. Mod. Phys. 73, 515-562

[74] Birch F 1947 Finite Elastic Strain of Cubic Crystal Phys. Rev. 71, 809-824 
[75] Angel R J 2000 Equations of State Rev. Mineral. Geochem. 41 35-60. EOSFIT 5.2 software, http://www.ccp14.ac.uk/ ccp/webmirrors/ross-angel/rja/soft/.10.2138/rmg.2000.41.2

[76] Coccioni M 2012 The LDA+U Approach: A Simple Hubbard Correction for Correlated Ground States. In: Correlated Electrons: From Models to Materials Modeling and Simulation, Vol. 2, Chapter 4; E. Pavarini, E. Koch, F. Anders, and M. Jarrell (ed.) (Berlin: Forschungszentrum Jülich)

[77] Dudarev S L, Nguyen Manh D and Sutton A P 1997 Effect of Mott-Hubbard Correlations on the Electronic Structure and Structural Stability of Uranium Dioxide Phil. Mag. B 75, 613628

[78] Crocombette J P, Jollet F, Thien Nga L and Petit T 2001 PlaneWave Pseudopotential Study of Point Defects in Uranium Dioxide Phys. Rev. B 64, 104107

[79] Nerikar P, Watanabe T, Tulenko J S, Phillpot S R and Sinnott S B 2009 Energetics of Intrinsic Point Defects in Uranium Dioxide from Electronic-Structure Calculations J. Nucl. Mater. 384, 61-69

[80] Weck P F, Kim E, Jové-Colón C F, Sassani D C 2013 On the Role of Strong Electron Correlations in the Surface Properties and Chemistry of Uranium Dioxide Dalton Trans. 42, 4570 4578

[81] Andersson D A, Baldinozzi G, Desgranges L, Conradson D R Conradson S D 2013 Density Functional Theory Calculations of $\mathrm{UO}_{2}$ Oxidation: Evolution of $\mathrm{UO}_{(2+\mathrm{x})}, \mathrm{U}_{4} \mathrm{O}_{(9-\mathrm{y})}, \mathrm{U}_{3} \mathrm{O}_{7}$, and $\mathrm{U}_{3}$ O8 Inorg. Chem. 52, 2769-2778

[82] Beridze G and Kowalski P M 2014 Benchmarking the DFT+U Method for Thermochemical Calculations of Uranium Molecular Compounds and Solids J. Phys. Chem. A 118 11797-11810

[83] Weck P F and Kim E 2014 Layered Uranium(VI) Hydroxides: Structural and Thermodynamic Properties of Dehydrated Schoepite $\alpha-\mathrm{UO}_{2}(\mathrm{OH})_{2}$ Dalton Trans. 43, 17191-17199

[84] Weck P F, Kim E and Buck E C 2015 On the Mechanical Stability of Uranyl Peroxide Hydrates: Implications for Nuclear Fuel Degradation RSC Adv. 5, 79090-79097

[85] Weck P F and Kim E 20116 Uncloaking the Thermodynamics of the Studtite to Metastudtite Shear-Induced Transformation J. Phys. Chem. C 120, 16553-16560

[86] Ostanin S and Zeller P 2007 Ab Initio Study of the Uranyl Oxide Hydrates: A Proton Transfer Mediated by Water J. Phys. Condens. Matter 19, 246108

[87] Ostanin S and Zeller P 2007 Ab initio study of uranyl peroxides: Electronic factors behind the phase stability Phys. Rev. B 75, 073101

[88] Colmenero F 2019 Structural, Spectroscopic, and Thermodynamic Characterization of Ammonium Oxalate Monohydrate Mineral Using Theoretical Solid-State Methods J. Phys. Chem. Solids 125, 31-42

[89] Mouhat F and Coudert F X 2014 Necessary and Sufficient Elastic Stability Conditions in Various Crystal Systems Phys. Rev. B 90, 224104

[90] Voigt W 1962. Lehrbuch der Kristallphysik (Leipzig: Teubner)

[91] Reuss A 1929 Berechnung der Fliessgrenze von Mischkristallen auf Grund der Plastizitatsbedingung fur Einkristalle Z. Angew. Math. Mech. 9, 49-58

[92] Hill R 1952 The Elastic Behaviour of a Crystalline Aggregate Proc. Phys. Soc. Lond. A 65, 349-354
[93] Pugh S F 1954 XCII. Relations between the Elastic Moduli and the Plastic Properties of Polycrystalline Pure Metals Phil. Mag. 45, 823-843

[94] Niu H, Wei P, Sun Y, Chen C X, Franchini C, Li, D and Li Y 2011 Electronic, Optical, and Mechanical Properties of Superhard Cold-Compressed Phases of Carbon Appl. Phys. Lett. 99, 031901.

[95] Ranganathan S I and Ostoja-Starzewski M 2008 Universal Elastic Anisotropy Index Phys. Rev. Lett. 101, 055504

[96] Bouhadda Y, Djella S, Bououdina M, Fenineche N and Boudouma Y 2012 Structural and Elastic Properties of $\mathrm{LiBH}_{4}$ for Hydrogen Storage Applications J. Alloys Compd. 534, 20-24

[97] Evans K E, Nkansah M A, Hutchinson I J and Rogers S C 1991 Molecular Network Design Nature 353, 124-124

[98] Marmier A, Lethbridge Z A D, Walton R I, Smith C W, Parker, S C and Evans K. E 2010 ElAM: A Computer Program for the Analysis and Representation of Anisotropic Elastic Properties Comput. Phys. Commun. 181, 2102-2115

[99] Binns J, Konstantin V, Kamenev K E R, Marriott G J, McIntyre S A, Moggach M M and Parsons S A 2016 Non-Topological Mechanism for Negative Linear Compressibility Chem. Commun. 52, 7486-7489

[100] Barnes D L 2017 Negative Linear Compressibility: Beyond the Wine-Rack Model and Towards Engineering Applications. Ph. D. Thesis. (Exeter: University of Exeter) 